\title{
MINIMUM SPANNING TREE PADA DISTRIBUSI BAHAN NASKAH USBN SD/MI DI KABUPATEN SRAGEN
}

\author{
NUGROHO ARIF SUDIBYO ${ }^{1}$, TRI PURWANTO ${ }^{2}$, DEDDY RAHMADI $^{3}$ \\ ${ }^{1}$ Universitas Duta Bangsa, Jl. Bhayangkara Tipes Serengan Kota Surakarta 57154 \\ nugroho_arif@udb.ac.id \\ ${ }^{2}$ Universitas Duta Bangsa, Jl. Bhayangkara Tipes Serengan Kota Surakarta 57154 \\ 190103246@fikom.udb.ac.id \\ ${ }^{3}$ Universitas Sebelas Maret, J1 Ir. Sutami no 36A, Jebres, Surakarta 57126 \\ deddyrahmadi07@gmail.com
}

First Received: 04-10-2020; Accepted: 26-10-2020

\begin{abstract}
Abstrak
Tujuan dari penelitian ini adalah untuk mengetahui penyelesaian minimum spanning tree terpendek untuk mendistribusikan naskah USBN SD/MI di Kabupaten Sragen. Digunakan Algoritma Kruskal dalam mencari rute terpendek dalam penelitian ini. Data dalam penelitian ini diperoleh dengan cara menghitung jarak antar titik secara langsung. Hasil penelitian menunjukkan bahwa minimum spanning tree yang diperoleh sebesar 112,2 km dihitung secara manual dan dengan bantuan program Tora.
\end{abstract}

Kata kunci: Minimum spanning tree; Algoritma Kruskal; USBN; Sragen

\section{IMPLEMENTATION MINIMUM SPANNING TREE ALGORITHM IN DISTRIBUTION USBN SD / MI MANUAL MATERIALS IN KLATEN DISTRICT}

\begin{abstract}
The purpose of this study was to determine the minimum completion of the shortest spanning tree to distribute the USBN SD / MI script in Sragen Regency. Kruskal's algorithm is used to find the shortest route in this study. The data in this study were obtained by directly calculating the distance between points. The results showed that the minimum spanning tree obtained was $112.2 \mathrm{~km}$, calculated manually and with the help of the Tora program.
\end{abstract}

Keywords: Minimum spanning tree; Kruskal algoritm; USBN; Sragen

\section{PENDAHULUAN}

Masalah menemukan minimum spanning tree untuk teori graf pasti mempunyai solusi. Bahkan dengan menggunakan komputer tercepat yang ada saat ini, memeriksa semua tree 
dalam graf dengan kira-kira 100 vertex akan membutuhkan lebih banyak waktu daripada yang diperkirakan untuk bertahan dalam kehidupan alam semesta (EPP, 2011).

Pada tahun 1956 dan 1957 Joseph B. Kruskal dan Robert C. Prim masing-masing menggambarkan algoritma yang jauh lebih efisien untuk membangun minimum spanning tree (Wamiliana, Usman, Warsono, Warsito, \& Daoud, 2020). Bahkan untuk graf yang cukup besar, kedua algoritma dapat diimplementasikan sehingga memakan waktu komputasi yang relatif singkat (Medak, 2018).

USBN dahulu dikenal sebagai US. Perbedaannya terletak pada standar yang digunakan. USBN memakai standard nasional, sedangkan US memakai standar sekolah. Terdapat tiga mata pelajaran dalam USBN yaitu Bahasa Indonesia, Matematika dan IPA (Mahmuzah, Aklimawati, Meylizza, \& Asri, 2019).

Bahan naskah USBN SD/MI didistribusikan dari tempat awal Dinas Pendidikan dan Kebudayaan Kabupaten Sragen ke Kantor UPT Dinas Pendidikan Kecamatan. Oleh karena itu, dalam makalah ini akan dibahas bagaimana penyelesaian minimum spanning tree terpendek untuk mendistribusikan naskah USBN SD/MI di Kabupaten Sragen.

\section{METODE PENELITIAN}

Notasi dan terminologi dalam penelitian ini mengacu pada (Sudibyo, Setyawan, \& Hidayat, 2020). Digunakan Algoritma Kruskal dalam mencari rute terpendek dalam penelitian ini. Data dalam penelitian ini diperoleh dengan cara menghitung jarak antar titik secara langsung.

Input: $\mathrm{G}$ [graf berbobot terhubung dengan $n$ vertex, di mana $n$ adalah bilangan bulat positif] Algoritm Body:

[Akan dibangun subgraf $T$ dari $G$ yang terdiri dari semua vertex $G$ dengan edge yang ditambahkan agar bobotnya bertambah. Pada setiap tahap, misalkan $m$ adalah jumlah sisi dari T.]

1. Inisialisasi $T$ memiliki semua vertex dari $G$ dan tidak ada $e d g e$.

2. Misalkan $E$ adalah himpunan dari semua edge $G$, dan misalkan $m:=0$.

3. While $(m<n-1)$

a. Temukan edge e di $E$ dengan bobot paling kecil.

b. Hapus $e$ dari $E$.

c. Jika penambahan $e$ ke himpunan edge $T$ tidak menghasilkan rangkaian kemudian tambahkan $e$ ke himpunan edge $T$ dan himpunan $m:=m+1$ 
end whilw

Output: $T$ [T adalah minimum spanning tree untuk $G$.]

\section{HASIL DAN PEMBAHASAN}

Diasumsikan Disdikbud dan UPTD sebagai vertex, dan jarak antar Disdikbud dan UPTD diasumsikan sebagai edge yang memiliki bobot.

Tabel 1. Kode Huruf dengan Keterangan tempat distribusi bahan naskah USBN SD/MI

\begin{tabular}{cl}
\hline Huruf & \multicolumn{1}{c}{ Keterangan } \\
\hline A & Disdikbud Kabupaten Sragen \\
B & UPTD Pendidikan Kec. Kalijambe \\
$\mathbf{C}$ & UPTD Pendidikan Kec. Plupuh \\
D & UPTD Pendidikan Kec. Masaran \\
E & UPTD Pendidikan Kec. Kedawung \\
F & UPTD Pendidikan Kec. Sambirejo \\
G & UPTD Pendidikan Kec. Gondang \\
H & UPTD Pendidikan Kec. Sambungmacan \\
$\mathbf{I}$ & UPTD Pendidikan Kec. Ngrampal \\
$\mathbf{J}$ & UPTD Pendidikan Kec. Karangmalang \\
$\mathbf{K}$ & UPTD Pendidikan Kec. Sragen \\
$\mathbf{L}$ & UPTD Pendidikan Kec. Sidoharjo \\
$\mathbf{M}$ & UPTD Pendidikan Kec. Tanon \\
$\mathbf{N}$ & UPTD Pendidikan Kec. Gemolong \\
$\mathbf{O}$ & UPTD Pendidikan Kec. Miri \\
$\mathbf{P}$ & UPTD Pendidikan Kec. Sumberlawang \\
$\mathbf{Q}$ & UPTD Pendidikan Kec. Mondokan \\
$\mathbf{R}$ & UPTD Pendidikan Kec. Sukodono \\
$\mathbf{S}$ & UPTD Pendidikan Kec. Gesi \\
$\mathbf{T}$ & UPTD Pendidikan Kec. Tangen \\
$\mathbf{U}$ & UPTD Pendidikan Kec. Jenar \\
\hline
\end{tabular}

Setelah dihitung jarak antar vertex seperti pada Tabel 2, akan dicari minimum spanning tree dari jarak yang sudah diperoleh dengan Algoritma Kruskal.

Tabel 2. Daftar Jarak antar tempat Distribusi bahan naskah USBN SD/ MI dalam kilometer 


\begin{tabular}{|c|c|c|c|c|c|c|c|c|c|c|c|c|c|c|c|c|c|c|c|c|c|}
\hline No & A & B & C & D & E & $\mathrm{F}$ & $\mathrm{G}$ & $\mathrm{H}$ & 1 & $\mathrm{~J}$ & K & $\mathrm{L}$ & M & $\mathrm{N}$ & 0 & P & Q & $\mathrm{R}$ & S & $\mathrm{T}$ & $\mathrm{U}$ \\
\hline A & & & & & & & & & 30 & 80 & 1.00 & 80 & 13.10 & 24.00 & 27.10 & 21.40 & 21.40 & 18.60 & 15.90 & 24.00 & 22.50 \\
\hline B & 8.80 & 00 & ).30 & .40 & .60 & 60 & 40.30 & 42.90 & 5.20 & 29.60 & 28.50 & 25.60 & 17.10 & 5.90 & 13.20 & 15.60 & 25.80 & 28.80 & 34.40 & 41.60 & 47.80 \\
\hline C & 670 & 30 & 0,0 & 810 & 120 & 15,20 & 29.80 & 29.90 & 24.80 & 19.10 & 18.10 & 15.10 & 11.00 & 9.30 & 17.20 & 15.60 & 16.70 & 19.60 & 24.70 & 32.40 & 38.30 \\
\hline D & & & 9 & 0.00 & & & 23.30 & 25.10 & 18.30 & 12.20 & 11.60 & & 13.80 & 17.10 & 25.70 & 22.30 & 23.40 & 21.90 & 25.20 & 33.30 & 35.40 \\
\hline E & 80 & 60 & 20 & 50 & 0.00 & 40 & 4.00 & 9.90 & 14.50 & 5.10 & 8.30 & 10.50 & 21.00 & 30.30 & 36.30 & 29.60 & 27.30 & 24.50 & 21.30 & 29.30 & 30.20 \\
\hline F & 1970 & 80 & 20 & 8.70 & 14.40 & 0.00 & 9.40 & 17.20 & 19.20 & 17.40 & 18.90 & 22.20 & 33.80 & 43.30 & 47.70 & 41.00 & 37.10 & 34.30 & 33.10 & 34.40 & 2450 \\
\hline $\mathrm{G}$ & 14.00 & 30 & .80 & .80 & . & . & 0.00 & 10.30 & 14.30 & 14.20 & 14.50 & 17.70 & 28.50 & 38.90 & 43.20 & 36.50 & 31.50 & 28.40 & 24.10 & 25.90 & 21.10 \\
\hline $\mathrm{H}$ & 19.70 & 5.60 & 35.20 & 25.10 & 19.90 & 17.20 & 10.30 & 0.00 & 8.20 & 13.90 & 12,70 & 16.30 & 22,40 & 37.40 & 40.50 & 33.80 & 25.40 & 22.40 & 18.00 & 19.80 & 13.40 \\
\hline I & 6.30 & 35.20 & 24.80 & 18.30 & 14.50 & 1920 & 1430 & 8.20 & 0.00 & 9.40 & 7.10 & 16.00 & 15.80 & 29.80 & 33.20 & 27.30 & 18.80 & 16.00 & 13.30 & 15.50 & 15.60 \\
\hline J & 3.80 & 29.60 & .10 & 20 & D.t. & 17.40 & 14.20 & 13.90 & 9.40 & 0.00 & 3.00 & 5.70 & 17.30 & 27.00 & 31.20 & 24.50 & 22.20 & 19.30 & 16.60 & 4.20 & 21.50 \\
\hline $\mathrm{K}$ & 1.00 & 28.50 & 8.10 & 11.60 & 8.30 & 18.90 & 14.50 & 12.70 & 7.10 & 3.00 & 0.00 & 9.20 & 15.10 & 25.20 & 30.50 & 23.80 & 19.50 & 16.70 & 13.50 & 22.20 & 24.20 \\
\hline $\mathrm{L}$ & 2.80 & 25.60 & 15.10 & 680 & 10.50 & 22.20 & 17.70 & 16.30 & 16.00 & 5.70 & 9.20 & 0.00 & 12.10 & 23.20 & 27.60 & 20.90 & 22.10 & 19.30 & 16.10 & 24.80 & 26.80 \\
\hline M & 10 & 10 & .00 & 0 & $2 \pi, 000$ & 33.80 & 20.20 & 22.40 & 15.80 & 17.30 & 15.10 & 12.10 & 0.00 & 10.70 & 16.00 & 9.30 & 10.50 & 13.30 & 18.40 & 26.10 & 32.30 \\
\hline $\mathrm{N}$ & 24.00 & 5.90 & 9.30 & 17.10 & 30.30 & 43.30 & 38.90 & 37.40 & 29.80 & 27.00 & 25.20 & 23.20 & 10.70 & 0.00 & 9.30 & 10.40 & 20.50 & 23.50 & 29.10 & 36.30 & 42.60 \\
\hline 0 & 27.10 & 13.20 & 17.20 & 25.70 & 36.30 & 47.70 & 43.20 & 40.50 & 33.20 & 31.20 & 30.50 & 27.60 & 16.00 & 9.30 & 0.00 & 7.30 & 17.50 & 20.50 & 26.10 & 33.30 & 39.50 \\
\hline $\mathrm{P}$ & 21.40 & 15.60 & 15.60 & 22.30 & 29.60 & 41.00 & 36.50 & 33.80 & 27.30 & 24.50 & 23.80 & 20.90 & 9.30 & 10,40 & 7.30 & 0.00 & 10.80 & 13.80 & 18.90 & 26.60 & 37.20 \\
\hline Q & 21.40 & 25.80 & 16.70 & 23.40 & 27.30 & 37.10 & 31.50 & 25.40 & 18.80 & 22.20 & 19.50 & 22.10 & 10.50 & 20.50 & 17.50 & 10.80 & 0.00 & 4.90 & 11.00 & 18.20 & 24.40 \\
\hline R & 18.60 & 28.80 & 19.60 & 21.90 & 24.50 & 34.30 & 28.40 & 22.40 & 16.00 & 19.30 & 16.70 & 19.30 & 13.30 & 23.50 & 20.50 & 13.80 & 4.90 & 0.00 & 6.80 & 13.20 & 20.30 \\
\hline $\mathrm{S}$ & 15.90 & 34.40 & 24,70 & 25.20 & 21.30 & 33.10 & 24.10 & 18.00 & 13.30 & 16.60 & 13.50 & 16.10 & 18.40 & 29.10 & 26.10 & 18.90 & 11.00 & 6.80 & 0.00 & 10.30 & 15.90 \\
\hline $\mathrm{T}$ & 24.00 & 41.60 & 32.40 & 33.30 & 29.30 & 34.40 & 25.90 & 19.80 & 15.50 & 24.20 & 22.20 & 24.80 & 26.10 & 36.30 & 33.30 & 26.60 & 18.20 & 13.20 & 10.30 & 0.00 & 13.80 \\
\hline $\mathrm{U}$ & 22.50 & 47.80 & 38.30 & 35.40 & 30.20 & 24.50 & 21.10 & 13.40 & 15.60 & 21.50 & 24.20 & 26.80 & 32.30 & 42.60 & 39.50 & 37.20 & 24.40 & 20.30 & 15.90 & 13.80 & 0.00 \\
\hline
\end{tabular}

Setelah dihitung secara manual dan dengan bantuan program Tora diperoleh hasil sebagai berikut.

\section{Updated minimal tree length $=112.20$}

0. Start at node $\mathrm{N} 1$

1. Connect $\mathrm{N} 11$ [Sragen] to $\mathrm{N} 1$ [Disdikbud]: Length $=1.00$

2. Connect N12 [Sidoharjo] to N1 [Disdikbud]: Length $=2.80$

3. Connect $\mathrm{N} 10$ [Karangmalang] to $\mathrm{N} 11$ [Sragen]: Length $=3.00$

4. Connect N9 [Ngrampal] to N11 [Sragen]: Length $=5.20$

5. Connect N5 [Kedawung] to $\mathrm{N} 10$ [Karangmalang]: Length $=6.30$

6. Connect N6 [Sambirejo] to N5 [Kedawung]: Length $=6.10$

7. Connect N8 [Sambungmacan] to N9 [Ngrampal]: Length $=7.10$

8. Connect N7 [Gondang] to N8 [Sambungmacan]: Length $=4.10$

9. Connect N4 [Masaran] to N12 [Sidoharjo]: Length $=7.60$

10. Connect N3 [Plupuh] to N4 [Masaran]: Length $=7.60$

11. Connect N13 [Tanon] to N3 [Plupuh]: Length $=6.10$

12. Connect N21 [Jenar] to N8 [Sambungmacan]: Length $=7.70$

13. Connect N20 [Tangen] to N21 [Jenar]: Length $=6.70$

14. Connect N19 [Gesi] to N20 [Tangen]: Length $=5.90$

15. Connect N18 [Sukodono] to N19 [Gesi]: Length $=6.40$

16. Connect $\mathrm{N} 17$ [Mondokan] to $\mathrm{N} 18$ [Sukodono]: Length $=2.80$

17. Connect N14 [Gemolong] to N3 [Plupuh]: Length $=8.30$

18. Connect N15 [Miri] to N14 [Gemolong]: Length $=3.70$

19. Connect N2 [Kalijambe] to N14 [Gemolong]: Length $=6.00$

20. Connect $\mathrm{N} 16$ [Sumberlawang] to $\mathrm{N} 15$ [Miri]: Length $=7.80$ 
Hasil minimum spanning tree diperoleh sebesar 112,2 km dihitung secara manual dan dengan bantuan program Tora. Hal tersebut membuktikan bahwa kombinatorik khususnya Algoritma Kruskal bisa digunakan untuk menyelesaikan kasus nyata (Afrianto \& Jamilah, 2012). Selain itu, Algoritma Kruskal terbukti salah satu algoritma efektif dalam mencari minimum spanning tree (Damayanti \& Rochmad, 2013) karena hasil minimum spanning tree yang diperoleh dibandingkan algoritma lain cukup baik (Prasetiyo, Mulyono, \& Mashuri, 2018).

\section{SIMPULAN}

Minimum spanning tree yang dicari menggunakan Algoritma Kruskal diperoleh sebesar 112,2 km dihitung secara manual dan dengan bantuan program Tora.

\section{UCAPAN TERIMA KASIH}

Universitas Duta Bangsa yang telah mendanai dan mendukung penelitian ini.

\section{DAFTAR PUSTAKA}

Afrianto, I., \& Jamilah, E. W. (2012). Penyelesaian Masalah Minimum Spanning Tree (MST) Menggunakan Ant Colony System (ACS) Jurnal Ilmiah Komputer dan Informatika (KOMPUTA). Ilmiah, Jurnal Komputa, Informatika, 1(2), 35-40.

Damayanti, A. A. \& Rochmad, R. A. (2013). Penerapan Algoritma Kruskal Pada Jaringan

Listrik Perumahan Kampoeng Harmoni Di Ungaran Barat. UNNES Journal of Mathematics, 2(1), 9-16.

EPP, S. S. (2011). Discrete Mathematics With Applications (fourth). Canada: Richard Stratton. Mahmuzah, R., Aklimawati, Meylizza, \& Asri, K. (2019). Pengaruh Nilai Ujian Sekolah Berstandar Nasional (USBN) terhadap Prestasi Belajar Siswa MTs Negeri Rukoh Kota Banda aceh pada Mata Pelajaran Matematika. Jurnal Serambi PTK, VI(2), 64-69.

Medak, J. (2018). Review and Analysis of Minimum Spanning Tree Using Prim's Algorithm. $6(2)$.

Prasetiyo, A., Mulyono, \& Mashuri. (2018). Penerapan Algoritma Kruskal Dan Sollin Pada Pendistribusian Air PDAM Tirta Aji Cabang Wonosobo Dan Penggunaan Microsoft Vb 6.0 Sebagai Pembandingnya. UNNES Journal of Mathematics, 7(2), 155-164.

Sudibyo, N. A., Setyawan, P. E., \& Hidayat, Y. P. S. R. (2020). Implementasi Algoritma Dijkstra Dalam Pencarian Rute Terpendek Tempat Wisata Di Kabupaten Klaten. Riemann: Research of Mathematics and Mathematics Education, 2(1), 1-9. 
Riemann Volume 2, No. 2, Oktober 2020, hal. 64-69

Wamiliana, Usman, M., Warsono, Warsito, \& Daoud, J. I. (2020). Using Modification Of Prim 's Algorithm And GNU Octave And To Solve The Multiperiods Installation Problem. IIUM Engineering Journal, 21(1), 100-112. 